\title{
Therapeutic Interventions for Itch in AD
}

\author{
Sonja Ständer, $M D^{1, *}$ \\ Ulrike Raap, $M D^{2}$
}

\author{
Address \\ ${ }^{*}, 1$ Department of Dermatology, Competence Center Chronic Pruritus, University \\ Hospital of Münster, Von-Esmarch-Strasse 58, 48149, Münster, Germany \\ e-mail: sonja.staender@uni-muenster.de \\ ${ }^{2}$ Department of Dermatology and Allergy, Hannover Medical School, Carl-Neuberg- \\ Str. 1, 30625, Hannover, Germany \\ e-mail: raap.ulrike@mh-hannover.de
}

Published online: 2 September 2014

(C) Springer International Publishing AG 2014

Keywords Atopic dermatitis - Pruritus - Itch - Neurokinin 1 receptor - Aprepitant - Histamine 4 receptor

\begin{abstract}
Atopic dermatitis (AD) is characterized by severe pruritus, which has a negative impact on the quality of life of patients. AD pruritus is usually of high intensity, occurs predominantly during the night and leads to severe scratching. Thus, the therapy has to focus not only on the suppression of the symptom but also on improvement of sleep and therapy of scratch lesions. Today, the therapy of AD pruritus is mainly based on conventional topical and systemic anti-inflammatory drugs and off-label application of mu-opioid receptor antagonists, the antidepressant mirtazapine, and - without evidence from controlled studies - the neurokinin-1 receptor antagonist aprepitant. The pathophysiology of ADassociated pruritus is still not fully understood; however, recent identification of several key mediators and mechanisms might enable development of novel therapies such as receptor antagonists for neurokinin 1, histamine 4, interleukin 31, thymic stromal lymphopoietin (TSLP), and nerve growth factor (NGF). Controlled studies that are currently being carried out can be expected to pave the way for improved treatment options in $A D$ pruritus.
\end{abstract}

\section{Opinion Paragraph}

Atopic dermatitis (AD) is a chronic inflammatory skin disease that has a major negative impact on the quality of life of patients because of the severe pruritus and skin inflammation associated with it. Pruritus is usually of high intensity, especially at night, and scratching leads to worsening of the skin condition. The current mainstays of AD therapy do not always result in adequate control of pruritus. Topical steroids and calcineurin inhibitors demonstrated antipruritic efficacy in clinical trials, while H1-antihistamines failed to have any impact on $\mathrm{AD}$ pruritus. However, in most patients, including children, topical therapies are not sufficient. To date, ultraviolet 
(UV) therapy and systemic cyclosporine are the only approved and evidence-based alternative therapy modalities in $\mathrm{AD}$ pruritus. The off-label use of the antidepressant mirtazapine and the expensive mu-opioid receptor antagonist naltrexone have been shown to have antipruritic effects; however, in view of the adverse effects of currently available systemic therapies, there are limitations with regard to their use in children and patients with certain comorbidities. A novel, very promising, approach in $\mathrm{AD}$ pruritus was identified by using the neurokinin-1 receptor (NK1R) antagonist aprepitant. By demonstrating rapid and high antipruritic effects, it confirms the important role of substance $P$ in AD pruritus. Currently, novel NK1R antagonists are undergoing randomized clinical trials in $\mathrm{AD}$ pruritus and will potentially help treatment of severe pruritus. Histamine- 4 receptor antagonism was shown in recent experimental studies to be a promising target. In addition, anti-interleukin-31 is in phase I clinical trial for the treatment of pruritus in $\mathrm{AD}$ patients. With the recent identification of additional mediators playing a role in the pathophysiology of pruritus in $\mathrm{AD}$, further target candidates are in line for investigation and will be suitable in the treatment of $\mathrm{AD}$ itch in the future. Of these, artemin, nerve growth factor (NGF), thymic stromal lymphopoietin (TSLP), and semamorphin 3A have been shown to affect pruritus.

\section{Introduction}

An essential feature of atopic dermatitis (AD) is pruritus, which, in addition to the psychologically disturbing presence of visible eczema, impairs the quality of life of patients [1]. AD pruritus has distinct characteristics in terms of severity and course. Recent web-based questionnaire studies demonstrated that patients judge their average pruritus intensity to be very high, and $40 \%$ of AD patients reported ten episodes and more of the symptom per day [2,3]. AD pruritus occurs over the whole body, with no sparing of certain areas; arms and face are most frequently involved, while armpits and plantar feet are affected rarely [2]. Patients experience itching throughout the whole day, but it is more frequent in the evening and at night [3]. Pruritus in $\mathrm{AD}$, because of its severity and continuous presence, represents a high burden for patients. Patients describe two types of $\mathrm{AD}$ pruritus: one type ('acute type') is associated with acute flare-ups and parallels the course of eczema; the other type ('chronic type') persists even after eczema has healed and is particularly present in those patients with severe scratch lesions, lichenifications, and prurigo lesions [3]. Both are exceedingly difficult to treat, but show some clinical differences in response to therapies.

Although pruritus is one of the main symptoms of $\mathrm{AD}$, its pathophysiology is still not fully understood. Over the past decade, many interesting mediators and mechanisms have been explored in $\mathrm{AD}$, offering for the first time some understanding of the mechanisms of action in itchy AD skin; however, the exact pathophysiology of itch in different stages and forms of $\mathrm{AD}$ remains unclear. Key players in AD itch are sensory nerves, keratinocytes, mast cells, and certain inflammatory cells. During an acute flare-up, inflammatory cells have a more prominent role, while, in the chronic stage of $\mathrm{AD}$, sensory nerves and neuropeptides are key players.

These new observations have the potential to help develop novel, targetspecific therapies. Some new drugs are currently being tested in clinical trials and are not yet available for routine use. The need for effective therapies to treat pruritus in $\mathrm{AD}$ is urgent, and the focus of several reviews and guidelines in the past years has been on establishing the best evidence-based approaches to treat 


\section{Treatment}

this symptom $[4,5 \bullet, 6 \bullet, 7,8 \bullet \bullet]$. Here, we present a selection of effective therapies in $\mathrm{AD}$ itch. For standard care, including general principles such as avoidance of pruritus triggers and emollient therapy to reduce dry skin and to improve barrier disturbance, we refer the reader to the current European guideline on the treatment of $\mathrm{AD}[5 \bullet, 6 \bullet]$.

\section{Topical Corticosteroids and Calcineurin Inhibitors}

A recent meta-analysis of therapy of $\mathrm{AD}$ pruritus identified 52 randomized controlled trials with adequate sample size and pruritus assessment [4]. Among these, 22 studies focused on the topical use of pimecrolimus (16 studies) or tacrolimus (six studies) twice daily. The calcineurin inhibitors block the release of several nuclear factor of activated T-cells (NFAT)-dependent cytokines, possibly inducing itch from a number of immune cells. Based on statistical analysis of data, the authors concluded that calcineurin inhibitors significantly reduced the pruritus of $\mathrm{AD}$ by $36 \%$ compared with the use of vehicle [4] (Table 1). Six studies reported similar results, namely reduction of $\mathrm{AD}$ pruritus by $34 \%$, when different topical corticosteroids (desonide hydrogel $0.05 \%$, clobetasol proprionate lotion, fluticasone proprionate $0.05 \%$ cream, prednicarbate 0.25 $\%$ ointment, hydrocortisone $1 \%$, methylprednisolone aceponate $0.1 \%$ cream) were used once or twice daily for treating AD-associated itch [4]. Both results parallel the clinical experience as summarized in the European guideline for the treatment of $\mathrm{AD}[5 \bullet, 6 \bullet]$ and chronic pruritus $[8 \bullet \bullet$. In acute flare-ups in $\mathrm{AD}$ patients, topical corticosteroids and calcineurin inhibitors have been found to be effective. Both of them are less effective in patients who suffer from severe itching along with mild to moderate eczema or show severe scratch lesions, which define the chronic stage of $\mathrm{AD}$ pruritus.

\section{Systemic H1 Antihistamines}

The effectiveness of $\mathrm{H} 1$ antihistamines in $\mathrm{AD}$ pruritus has not yet been demonstrated. The meta-analysis mentioned above concluded that, in one study addressing cetirizine, $\mathrm{H} 1$ antihistamines (in licensed dosage) demonstrated no significant effect [4]. A systematic review of antihistamine use in eczema concluded that there is currently no high-level evidence to support or refute the efficacy or safety of oral $\mathrm{H} 1$ antihistamines used as monotherapy for eczema [9]. Of note, the authors identified 757 studies; however, no randomized controlled trial met their inclusion criteria. No definite conclusions on the antipruritic effects of $\mathrm{H} 1$ antihistamines could be drawn, because, in most studies, patients received other concomitant therapies [9]. Also, according to the European guideline for $\mathrm{AD}$, there is not enough evidence to support the general use of either first- or second-generation $\mathrm{H} 1$ antihistamines for treatment of pruritus in $\mathrm{AD}[5 \bullet$. The European guideline on chronic pruritus comes to the same conclusion, but points out that first-generation antihistamines can be used to

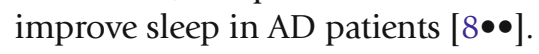

\section{Mu-Opioid Receptor Antagonists}

Oral or intravenous mu-opioid receptor antagonists are applied in opioid drug abuse or drug overdose [10]. They have a certain role in cholestatic pruritus and 


\begin{tabular}{|c|c|c|c|}
\hline Substance & Route & Mechanism & Evidence $^{a}$ \\
\hline Pimecrolimus, tacrolimus & Topical & Suppression of inflammation & $\begin{array}{l}\mathrm{RCT} \text {, meta-analysis, guideline } \\
\text { recommendation }\end{array}$ \\
\hline $\begin{array}{l}\text { Desonide, clobetasol } \\
\text { proprionate, fluticasone } \\
\text { proprionate, prednicarbate, } \\
\text { hydrocortisone, } \\
\text { methylprednisolone } \\
\text { aceponate, fluocinonide }^{b}\end{array}$ & Topical & Suppression of inflammation & $\begin{array}{l}\text { RCT, meta-analysis, guideline } \\
\text { recommendation, RCT } \\
\text { currently being performed } \\
\text { (NCT01469767) }\end{array}$ \\
\hline $\begin{array}{l}\text { H1-antihistamines (first and } \\
\text { second generation) }\end{array}$ & Oral & $\begin{array}{l}\text { Antagonist at the neuronal } \\
\text { histamine-1 receptor }\end{array}$ & $\begin{array}{l}\text { RCT, meta-analysis, systematic } \\
\text { review, guideline } \\
\text { recommendation }\end{array}$ \\
\hline Narrowband UVB & UV therapy & $\begin{array}{l}\text { Suppression of inflammation, } \\
\text { reduction of number of } \\
\text { cutaneous nerve fibers, } \\
\text { normalization of NGF and } \\
\text { semaphorin } 3 \mathrm{~A} \text { imbalance }\end{array}$ & $\mathrm{RCT}$, guideline recommendation \\
\hline Cyclosporine & Oral & Suppression of inflammation & $\mathrm{RCT}$, guideline recommendation \\
\hline Nalmefene, naltrexone & Oral & $\begin{array}{l}\text { Antagonist at the neuronal mu- } \\
\text { opioid-receptor }\end{array}$ & $\mathrm{RCT}$, guideline recommendation \\
\hline Mirtazapine & Oral & Tetracyclic antidepressant & $\begin{array}{l}\text { Case report, guideline } \\
\text { recommendation }\end{array}$ \\
\hline Aprepitant, VLY-686 ${ }^{\mathrm{b}}$ & Oral & Neurokinin-1 receptor antagonist & $\begin{array}{l}\text { Case series, guideline } \\
\text { recommendation, RCT } \\
\text { currently being performed } \\
\text { (NCT02004041) }\end{array}$ \\
\hline $\mathrm{CT}_{2} 27^{+}$ & Topical & $\begin{array}{l}\text { Antagonist at the high-affinity re- } \\
\text { ceptor TrkA }\end{array}$ & $\begin{array}{l}\text { RCT currently being performed } \\
\text { (NCT01808157) }\end{array}$ \\
\hline JNJ7777120, JNJ39758979 & Oral & $\begin{array}{l}\text { Antagonist at the histamine- } 4 \text { re- } \\
\text { ceptor on mast cells and T cells }\end{array}$ & $\begin{array}{l}\text { Experimental human and murine } \\
\text { studies, RCT (NCT01497119) } \\
\text { terminated prematurely due to } \\
\text { two cases of agranulocytosis }\end{array}$ \\
\hline IL-31-mAb ${ }^{b}$ & Subcutaneous & Neutralization of IL-31 & $\begin{array}{l}\text { Experimental human and murine } \\
\text { studies, phase I study } \\
\text { currently being performed } \\
\text { (NCT01614756) }\end{array}$ \\
\hline Semaphorin $3 A$ & Topical & Replacement in epidermis & $\begin{array}{l}\text { Preclinical evidence from animal } \\
\text { studies }\end{array}$ \\
\hline
\end{tabular}

AD pruritus. Based on results of four randomized controlled trials, the European guideline on chronic pruritus recommends the use of nalmefene (not available in each country) and naltrexone (50-100 mg/day) in severe pruritus of $\mathrm{AD}[8 \bullet \bullet]$. According to our experience, the frequent occurrence of side effects such as nausea and dizziness is a limitation in the use of these substances. Before offering this treatment, most effective in chronic and pruriginous forms 
of $\mathrm{AD}$, patients must be given comprehensive information on these unwanted side effects.

Antidepressants are widely used in pain and pruritus therapy in order to suppress the symptom and to treat potential psychogenic factors. However, there is not much evidence on the use of antidepressants in $\mathrm{AD}$ pruritus. The European guideline on chronic pruritus refers to one case report using the tetracyclic antidepressant mirtazapine $(15 \mathrm{mg} /$ day) in the treatment of ADassociated pruritus $[8 \bullet \bullet$. Despite the absence of studies on the use of modern antidepressants, our own experience points to a weak effect of selective serotonin reuptake inhibitors and amitriptyline in AD pruritus.

\section{Cyclosporine}

Cyclosporine is an immunosuppressant that is recommended by the European guideline for treatment of chronic pruritus in $\mathrm{AD}$. This recommendation is based on two randomized controlled trials demonstrating its antipruritic effects $[8 \bullet \bullet$. Based on our own experience, AD pruritus is relieved by cyclosporine ( 5 $\mathrm{mg} / \mathrm{kg}$ body weight) within the first few days of therapy, while more time is needed for improvement of eczema. These observations suggest that, in addition to modulating inflammatory cells such as type 2 helper (TH2), TH22, and TH17 cells [11], cyclosporine may have impact on pruritogenic factors.

Ultraviolet (UV) irradiation is a standard therapy in $\mathrm{AD}$ and relieves $\mathrm{AD}$ pruritus. Narrowband UVB was shown to be more effective in AD pruritus than UVA and UVA1 $[5 \bullet, 8 \bullet \bullet$. UV therapy seems to influence the pathophysiology of $\mathrm{AD}$ pruritus, possibly by reducing the number of cutaneous nerve fibers and normalizing the imbalance between nerve growth factor (NGF) and semaphorin 3A levels in the epidermis [12].

To date, no treatment is specifically licensed for the therapy of AD itch. However, therapies available for AD in general can be applied to address the symptom. If not sufficient, off-label substances can be used.

\section{Novel Mechanisms, Novel Targets, and Potential Future Treatment Options}

\section{Mechanisms in Acute Itch of AD: Mediators of Inflammation}

\section{Interleukin-31}

Interleukin (IL)-31 represents a novel T-cell cytokine that is increased in AD serum and skin levels. Interestingly, IL-31 serum levels correlate with disease severity in adults and in children with AD [13•]. IL-31 was found to affect the functional activity of peripheral blood eosinophils, which are effector cells in $\mathrm{AD}$ [14]. In a mouse model showing features of AD, an IL-31 antagonist significantly inhibited scratching activity. Injecting IL-31 in human skin in an experimental design with skin prick test, IL-31 induced no immediate itch in AD patients and healthy controls [15]. However, it is still believed that IL-31 plays a role in pruritus since a sensory neuron-expressed IL-31 receptor mediates TH 
cell-dependent itch [16]. Currently, a phase I clinical trial using a single dose of IL-31 monoclonal antibody ( $\mathrm{mAb}$ ) in $\mathrm{AD}$ patients in comparison with healthy subjects is being conducted in the USA, and, if anti-IL-31 works as effectively against pruritus in humans as in the mouse model, some exciting results can be expected.

\section{Interleukin-33}

IL-33 has been suggested as playing a role in the transmission of AD pruritus. Transgenic mice expressing IL-33 in the skin developed spontaneous itchy dermatitis [17]. In the lesional skin of these mice, the epidermis was thickened and eosinophils were infiltrated, with increased expression of the eosinophil peroxidase and major basic protein genes, features resembling those in $\mathrm{AD}$. In AD patients, IL-33 and interferon (IFN)- $\gamma$ are closely interlinked in epidermal inflammation. IFN- $\gamma$ induces IL-33 in keratinocytes, and IL-33 acts on activated $\mathrm{T}$ cells to further increase the release of IFN- $\gamma$, thus contributing to drive skin inflammation towards chronic responses [18]. Thus, anti-IL-33 seems to be a doubly interesting target, namely for treatment of the chronic inflammatory skin response in $\mathrm{AD}$ and for pruritus.

\section{Histamine-4 Receptor Antagonists}

Histamine is supposed to drive pruritus in inflammatory skin diseases. However, in $\mathrm{AD}, \mathrm{H} 1$ antihistamines have not been as efficacious in treating pruritus as in chronic spontaneous urticaria [19]. Recent data show that, in addition to $\mathrm{H} 1$ receptors, $\mathrm{H} 4$ receptors play a pivotal role in Th2 cell infiltration and cytokine secretion in allergic inflammatory skin, suggesting that $\mathrm{H} 4$ receptor antagonists may represent a novel therapeutic approach [20•]. In a mouse model showing features of $\mathrm{AD}$, the $\mathrm{H} 4$ receptor antagonist JNJ7777120 significantly inhibited pruritus and skin inflammation [21]. However, in a recent study in mice also featuring characteristics of $\mathrm{AD}$, the $\mathrm{H} 4$ receptor antagonist was not effective in the treatment of pruritus and skin inflammation [22]. In $\mathrm{AD}$ patients, histamine induces proliferation of keratinocytes via the $\mathrm{H} 4$ receptor, suggesting this to be a mechanism contributing to the epidermal hyperplasia observed in patients with $\mathrm{AD}$ [23]. Indeed, the $\mathrm{H} 4$ receptor seems to be crucial in the regulation of pruritus in humans since the $\mathrm{H} 4$ receptor antagonist JNJ39758979 was effective in reducing histamine-induced pruritus. This was

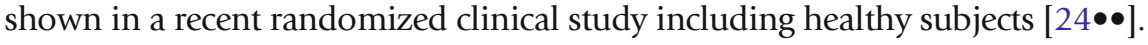

\section{Thymic Stromal Lymphopoietin}

Thymic stromal lymphopoietin (TSLP) is increased in the stratum corneum of AD patients and correlates with disease severity [25]. Production of TSLP by keratinocytes and dendritic cells is increased in AD [26]. The receptor of this cytokine is present on Th2 cells, dendritic cells, mast cells, and type 2 innate lymphoid cells [26]. Most recently, the receptor was found on murine neurons, and, upon injection into murine skin, TSLP was demonstrated to induce

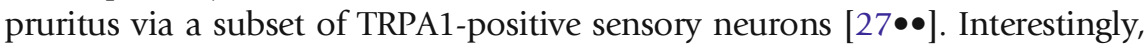
proteinase-activated receptor (PAR)-2 signaling promotes the release of TSLP from keratinocytes. It is well known that PAR2 is involved in AD itch [28], 
although the exact mechanisms are still under debate [29]; the link to TSLP offers an explanation for the induction of pruritus in $\mathrm{AD}[27 \bullet \bullet]$.

\section{Mechanisms in Chronic Itch of AD: Neuronal Factors Predominate}

\section{Hyperinnervation of the Skin}

Hyperinnervation and hypersensitivity of cutaneous nerves has been described in chronic $\mathrm{AD}$ [12]. This affects all nerve fibers, including different classes of $\mathrm{C}$ fibers, which transmit painful sensations. Accordingly, AD patients experience itch with painful subqualities such as stinging, pinching, and stabbing [30]. Tominaga and Takamori [12] speculate that hyperinnervation in AD is mainly caused by an imbalance between nerve elongation factors (e.g., NGF, amphiregulin, artemin) and nerve repulsion factors (e.g., semaphorin 3A, anosmin-1) produced by keratinocytes [12]. Artemin-expressing skin fibroblasts are increased in lesional skin of $\mathrm{AD}[31 \bullet \bullet]$. Since artemin is a member of glial cell line-derived neurotrophic factors (GDNFs), which is released by dermal fibroblasts after stimulation with substance P (SP), it is supposed that it induces peripheral nerve hyperinnervation, leading to abnormal acitivity and thermal hyperalgesia $[31 \bullet \bullet]$. Thus, artemin seems to lower the threshold of temperature-dependent itch sensation and might therefore be a novel therapeutic target for treating pruritic skin disorders, including AD.

NGF is present in keratinocytes, and high levels of this signaling molecule are released in $\mathrm{AD}$. NGF plays a key role in hyperinnervation in $\mathrm{AD}$, in which it also correlates with disease severity $[1,12]$. In addition, NGF contributes to hypersensitivity (peripheral sensitization) of cutaneous C-fibers [32] and thus represents an interesting therapy target in $\mathrm{AD}$. In fact, an antagonist of the highaffinity receptor for NGF (TrkA) is currently being investigated in AD pruritus (Table 1). Another new target is semaphorin 3A, which inhibits NGF-induced sprouting of nerves. As it is decreased in AD patients, semaphorin $3 \mathrm{~A}$ replacement has been proposed as a promising approach in the treatment of $\mathrm{AD}$ [12]. In murine models, a 4-day topical treatment inhibited scratching behavior and improved eczema scores [33••]; human studies are yet to be performed.

\section{Eosinophils}

In $\mathrm{AD}$ skin, eosinophil granule proteins are present in the same region as increased nerves $[34 \bullet \bullet]$. In co-cultures, eosinophils dramatically increased branching of sensory neurons isolated from the dorsal root ganglia (DRG) of mice $[34 \bullet \bullet]$. DRG neurons express eotaxin-1, intercellular adhesion molecule (ICAM)-1, and vascular cell adhesion molecule (VCAM)-1, which may be important in the recruitment, binding, and activation of eosinophils in the region of cutaneous nerves. Together, these data indicate a pathophysiological role of eosinophils in cutaneous nerve growth in $\mathrm{AD}$, suggesting eosinophils as a potentially interesting therapeutic target in $\mathrm{AD}$.

\section{Neuropeptides and Neurokinin-1 Receptor Antagonists}

Another interesting novel approach in the therapy of AD pruritus is SP antagonism. Nerve fibers in $\mathrm{AD}$ express a large number of neuropeptides. Among them, SP, which correlates with disease severity in $\mathrm{AD}$, was demonstrated to be increased already a long time ago [35]. SP binds to the neurokinin-1 receptor 
(NK1R), which is present on keratinocytes, mast cells, and vessels. Recently, several studies demonstrated that antagonization of efferent SP effects may also suppress pruritus effectively in $\mathrm{AD}$ [36]. In a case series, 20 patients with chronic, therapy-refractory pruritus of various origins reported a high antipruritic effect of the NK1R antagonist aprepitant $80 \mathrm{mg} /$ day for 1 week [37]. Among these, patients with atopic predisposition showed a good symptom response, as indicated by a drop of over 4 points on the visual analog scale ( $0-10$ points; 0 indicates no pruritus; 10 indicates worst imaginable pruritus). Based on patient experience, aprepitant seems to be efficacious in AD pruritus. Randomized controlled trials are currently being performed (Table 1).

\section{Acknowledgments}

The authors would like to thank Rajam Csordas-Iyer for assistance in the preparation of the manuscript.

\section{Compliance with Ethics Guidelines}

\section{Conflict of Interest}

Sonja Ständer declares that she has no conflict of interest.

Ulrike Raap declares that she has no conflict of interest.

Human and Animal Rights and Informed Consent

This article does not contain any studies with human or animal subjects performed by any of the authors.

\section{References and Recommended Reading}

Papers of particular interest, published recently, have been highlighted as:

- Of importance,

$\bullet$ Of major importance

1. Oh SH, Bae BG, Park CO, et al. Association of stress with symptoms of atopic dermatitis. Acta Derm Venereol. 2010;90:582-8.

2. O'Neill JL, Chan YH, Rapp SR, et al. Differences in itch characteristics between psoriasis and atopic dermatitis patients: results of a web-based questionnaire. Acta Derm Venereol. 2011;91:537-40.

3. Dawn A, Papoiu AD, Chan YH, et al. Itch characteristics in atopic dermatitis: results of a web-based questionnaire. Br J Dermatol. 2009; 160:642-4.

4. Sher LG, Chang J, Patel IB, et al. Relieving the pruritus of atopic dermatitis: a meta-analysis. Acta Derm Venereol. 2012;92:455-61.

5. $\quad$ Ring J, Alomar A, Bieber T, et al. Guidelines for treatment of atopic eczema (atopic dermatitis) part I. J Eur Acad Dermatol Venereol. 2012;26:1045-60.

This is a must-read European guideline that summarizes the current treatment options in AD.
6. Ring J, Alomar A, Bieber T, et al. Guidelines for treatment of atopic eczema (atopic dermatitis) Part II. J Eur Acad Dermatol Venereol. 2012;26:1176-93.

This is a must-read European guideline that summarizes the current treatment options in AD.

7. Yarbrough KB, Neuhaus KJ, Simpson EL. The effects of treatment on itch in atopic dermatitis. Dermatol Ther. 2013;26:110-9.

8.• Weisshaar E, Szepietowski JC, Darsow U, et al. European guideline on chronic pruritus. Acta Derm Venereol. 2012;92:563-81.

Comprehensive and must-read guideline for the treatment of patients with chronic pruritus.

9. van Zuuren EJ, Apfelbacher CJ, Fedorowicz Z, et al. No high level evidence to support the use of oral $\mathrm{H} 1$ antihistamines as monotherapy for eczema: a summary of a Cochrane systematic review. Syst Rev. 2014;3:25. 
10. Phan NQ, Bernhard JD, Luger TA, et al. Antipruritic treatment with systemic $\mu$-opioid receptor antagonists: a review. J Am Acad Dermatol. 2010;63:680-8.

11. Khattri S, Shemer A, Rozenblit M, et al. Cyclosporine in patients with atopic dermatitis modulates activated inflammatory pathways and reverses epidermal pathology. J Allergy Clin Immunol. 2014;133:1626-34.

12. Tominaga $\mathrm{M}$, Takamori $\mathrm{K}$. Itch and nerve fibers with special reference to atopic dermatitis: therapeutic implications. J Dermatol. 2014;41:205-12.

13.• Raap U, Weißmantel S, Gehring M, et al. IL-31 significantly correlates with disease activity and Th2 cytokine levels in children with atopic dermatitis. Pediatr Allergy Immunol. 2012;23:285-8.

This clinical study showed that IL-31 serum levels are increased in children with $\mathrm{AD}$ and correlate with disease severity in addition to Th2 cytokines, including IL-4 and IL-13.

14. Wong CK, Leung KM, Qiu HN, et al. Activation of eosinophils interacting with dermal fibroblasts by pruritogenic cytokine IL-31 and alarmin IL-33: implications in atopic dermatitis. PLoS One. 2012;7:e29851.

15. Hawro T, Sluja R, Weller K, et al. Interleukin-31 does not induce immediate itch in atopic dermatitis patients and healthy controls after skin challenge. Allergy. 2014;69:113-7.

16. Cevikbas H, Wang $X$, Akiyama T, et al. A sensory neuron-expressed IL-31 receptor mediates T helper celldependent itch: involvement of TRPV1 and TRPA1. J Allergy Clin Immunol. 2014;133:448-60.

17. Imai Y, Yasuda K, Sakaguchi Y, et al. Skin-specific expression of IL-33 activates group 2 innate lymphoid cells and elicits atopic dermatitis-like inflammation in mice. Proc Natl Acad Sci U S A. 2013;110:13921-6.

18. Seltmann J, Werfel T, Wittmann M. Evidence for a regulatory loop between IFN- $\gamma$ and IL-33 in skin inflammation. Exp Dermatol. 2013;22:102-7.

19. Raap U, Kapp A, Wedi B, Ständer S. Pruritus and urticaria. Hautarzt. 2011;61:737-42.

20. Mahapatra S, Albrecht M, Behrens B, et al. Delineating the role of histamine-1- and -4-receptors in a mouse model of Th2-dependent antigen-specific skin inflammation. PLoS One. 2014;4:87296.

This comprehensive study using an adoptive transfer model for antigen-specific Th cells showed that H1- and H4-receptors play a crucial role for Th2 migration and cytokine secretion in a Th2-driven model of skin inflammation.

21. Ohsawa Y, Hirasawa N. The antagonism of histamine $\mathrm{H} 1$ and $\mathrm{H} 4$ receptors ameliorates chronic allergic dermatitis via anti-pruritic and anti-inflammatory effects in NC/Nga mice. Allergy. 2012;67:1014-22.

22. Kamo A, Negi O, Tengara S, et al. Histamine H(4) receptor antagonists ineffective against itch and skin inflammation in atopic dermatitis mouse model. J Invest Dermatol. 2014;134:546-8.

23. Glatzer F, Geschwandtner M, Ehling S, et al. Histamine induces proliferation in keratinocytes from patients with atopic dermatitis through the histamine 4 receptor. J Allergy Clin Immunol. 2013;132:1358-67.
24.• Kollmeier A, Francke K, Chen B, et al. The histamine $\mathrm{H}_{4}$ receptor antagonist, JNJ 39758979, is effective in reducing histamine-induced pruritus in a randomized clinical study in healthy subjects. J Pharmacol Exp Ther. 2014;350(1):181-7.

This is the first study in which the H4 receptor antagonist JNJ 30758979 was used to analyze its effect on histamine-induced pruritus in humans. Of 24 healthy subjects, 23 finished the study, which showed a significant effect on inhibiting the histamine-induced pruritus, whereas there was no impact on wheal and flare reaction at the skin.

25. Sano Y, Masuda K, Tamagawa-Mineoka R, et al. Thymic stromal lymphopoietin expression is increased in the horny layer of patients with atopic dermatitis. Clin Exp Immunol. 2013;171:330-7.

26. Turner MJ, Zhou B. A new itch to scratch for TSLP. Trends Immunol. 2014;35:49-50.

27.• Wilson SR, Thé L, Batia LM, et al. The epithelial cellderived atopic dermatitis cytokine TSLP activates neurons to induce itch. Cell. 2013;155:285-95.

This novel study supports a model whereby calcium-

dependent TSLP release by keratinocytes activates both primary afferent neurons and immune cells to promote inflammatory responses in the skin and airways.

28. Nakagawa H, Hiura A. Four possible itching pathways related to the TRPV1 channel, histamine, PAR-2 and serotonin. Malays J Med Sci. 2013;20:5-12.

29. Liu Q, Weng HJ, Patel KN, et al. The distinct roles of two GPCRs, MrgprC11 and PAR2, in itch and hyperalgesia. Sci Signal. 2011;4:ra45.

30. Brenaut E, Garlantezec R, Talour K, et al. Itch characteristics in five dermatoses: non-atopic eczema, atopic dermatitis, urticaria, psoriasis and scabies. Acta Derm Venereol. 2013;93:573-4.

31.• Murota H, Izumi M, Abd El-Latif M, et al. Artemin causes hypersensitivity to warm sensation, mimicking warmth-provoked pruritus in atopic dermatitis. J Allergy Clin Immunol. 2012;130:671-82.

This is the first study revealing that AD fibroblasts are a source of artemin, a glia cell line-derived neurotrophic factor that induces proliferation of nerve cells with abnormal hyperinnervation and thermal hyperalgesia, suggesting that artemin lowers the threshold of temperature-dependent itch sensation. 32. Rukwied RR, Main M, Weinkauf B, et al. NGF sensitizes nociceptors for cowhage- but not histamine-induced itch in human skin. J Invest Dermatol. 2013;133:26870.

33.• Negi $\mathrm{O}$, Tominaga $\mathrm{M}$, Tengara $\mathrm{S}$, et al. Topically applied semaphorin 3A ointment inhibits scratching behavior and improves skin inflammation in NC/Nga mice with atopic dermatitis. J Dermatol Sci. 2012;66:37-43.

In this study of a mice model featuring characteristics of atopic dermatitis, semaphorin inhibited pruritus, improved transepidermal water loss and reduced densities of SP and PGP 9.5-positive nerve fibers in the epidermis in addition to reduced numbers of inflammatory cells including eosinophils and T cells, suggesting that semaphorin is a promising therapeutic target in AD. 
34.• Foster EL, Simpson EL, Fredrikson LJ, et al. Eosinophils increase neuron branching in human and murine skin and in vitro. PLoS One. 2011;6:22029.

This is an interesting study, revealing that human AD skin is featured by eosinophil granule proteins present in the same region as increased peripheral nerves. Further, in co-cultures, eosinophils were shown to dramatically increase the branching of sensory neurons isolated from DRG of mice.
35. Fantini F, Pincelli C, Romualdi $P$, et al. Substance P levels are decreased in lesional skin of atopic dermatitis. Exp Dermatol. 1992;1:127-8.

36. Ständer S, Luger TA (2015). NK-1 antagonists and itch. In: Cowan A, Yosipovitch G (eds) Pharmacology of itch. Springer, in press.

37. Ständer S, Siepmann D, Herrgott I, et al. Targeting the neurokinin receptor 1 with aprepitant: a novel antipruritic strategy. PLoS One. 2010;5:e10968. 